\title{
Advanced Fault-tolerant Control Strategy of Wind Turbine Based on Squirrel Cage Induction Generator with Rotor Bar Defects
}

\author{
Boubakeur ROUABAH ${ }^{1}$, Houari TOUBAKH ${ }^{2}$, and Moamar SAYED-MOUCHAWEH ${ }^{3}$ \\ ${ }^{1}$ Automatic Laboratory, Department of Electrical Engineering, Ferhat Abbas University, Sétif, 19000, Algeria \\ boubakeurrouabah@yahoo.fr \\ ${ }^{2}$ Laboratoire de génie électrique, Kasdi Merbah University, Ouargla Route de Ghardaia, BP.511, 30 000, Algeria \\ houari.toubakh@univ-ouargla.dz \\ ${ }^{3}$ Mines-Douai, Douai, IA, F-59500, France \\ moamar.sayed-mouchaweh@imt-lille-douai.fr
}

\begin{abstract}
Several research works in Wind Energy Conversion Systems (WECS) based on Squirrel Cage Induction Generator (SCIG) are developed for isolated site applications. Where, WECS are usually controlled by the Maximum Power Point Trucking (MPPT) algorithm in order to extract the maximum power from wind with constant operating point of SCIG. However, this WECS based on SCIG generator suffers from the problem of breaking rotor bars, therefore a failure in rotor bars is particularly a challenging task because: 1) it can change the operating point generated by MPPT algorithm, 2) increase mechanical vibrations, 3) affect the operation of gearbox, 4) inject a harmonic current in the grid. Therefore, Fault Tolerant Control (FTC) scheme is necessary to allow an optimum energy production, to reduce the maintenance costs and to increase the WECS availability. In this work, a new fault diagnosis approach based on frequency analysis of stator currents is used to detect the failure in bars of SCIG, then FTC algorithm is developed to adjust the pitch angle in max wind speed zone by determining a new operating point according to the wind speed, which leads to extend the lifetime of WECS. Simulation results using MATLAB SIMULINK showed a nominal current in healthy rotor bars and the lifetime of WECS was increased.
\end{abstract}

\section{INTRODUCTION}

Nowadays, the high dependence of human life and global economies on electric power generated from fossil fuels, increase the environmental pollutions concerns, these Rouabah Boubakeur et al. This is an open-access article distributed under the terms of the Creative Commons Attribution 3.0 United States License, which permits unrestricted use, distribution, and reproduction in any medium, provided the original author and source are credited. motivates the development of environmentally compatible energy. Wind energy conversion systems (WECS) are clean, cost effective, low carbon and sustainable efficient energy resource in the world (Luo et al, 2014. Fernando et al, 2007). A $666.1 \mathrm{GW}$ of electric power in 2019 will be generated from wind in worldwide (Md Emrad,1, 2017). until 2030 in USA, the total wind energy installed will be $20 \%$ of power demand (Md Emrad, 2018); in 2035 a 25\% of global power demand will be from renewable energy according to the international energy agency (IEA), and the fourth of this will be supplied from wind energy as mentioned in (Md Emrad, 2,2017) and the European Wind Energy Association (EWEA) has planned to provide $28.5 \%$ of European electricity needs with wind power in 2030 (Chen, 2013).

Hence, squirrel cage induction generators (SCIG) have been used in fixed and variable speed applications and remote sites due to simple structure (brush-less cage rotor and stator can be connected directly to the grid through transformer), lower cost, better reliability and robustness (Rahimi and Asadi, 2019), the SCIGs are used in remote areas of WECS because they do not need an external power supply to produce the excitation magnetic field (seyoum et al, 2003), however, the direct connection to the grid influence the power system by fluctuation of output voltage because of the wind speed is variable and the output power of wind turbine is proportional with cube of wind speed (Duong et al, 2014).

In literature, several researches that focused on power quality improvement and how to maintain the output of SCIG wind farm smooth and stable. In (Duong et al, 2014) simulation results showed good performance of pitch angle control in wind turbine based SCIG for all operating regions in power quality enhancement and smoothing output of SCIG.

However, a cracked or broken rotor bars can cause a rotor asymmetry, unbalanced grid voltages, fluctuant torque 
(Toliyat et al, 2013), mechanical stress, thermal stress and magnetic stress, this defects in rotor cage represents about $5 \%$ to $10 \%$ of machine faults (Md Emrad,1, 2017), and as wind turbines are usually installed at onshore remote sites and offshore it is important to avoid costly unscheduled repairs (Lešić et al, 2013), and assure the minimum generation of power until the arrival of the maintenance team. Therefore, the challenge is to improve reliability and sustainability of WECS under faulty conditions with fault tolerant control (FTC).

Several research work in literature use diagnostic methods to detect the defect rotor bars in SCIG, experimental results in (Lahcène et al, 2016) demonstrate the effectiveness of diagnostic method by analyzing stator current signature in broken rotor bar SCIG, in (Park et al, 2012) a Fast Fourier Transform (FFT) of stator current to detect the faults in SCIG, in (Obaid et al, 2016) a model-based Support Vector Classification (SVC) method to test experimentally the sanity of rotor bars at full load conditions, a rotor torque monitoring method with finite element to detect the failures in rotor bars of SCIG, in (Lešić et al, 2013) fault tolerant control scheme of variable pitch variable speed wind turbine to detect faults in rotor bars in order to avoid wind turbine shutdown.

In this paper a fault tolerant control by changing the pitch angle according to new operating point of SCIG with failure rotor bars, this new operating point is calculated from diagnosis signals and reference of currents in rotor bars

This paper is organized as follow: proposed structure modeling in section 2 , proposed approach in section 3 , and simulation results in section 4, finally conclusion in section 5 .

\section{Proposed STRUCTURE MODELING}

As shown in Fig.1 wind energy conversion system based SCIG fed electric load in isolate site, the wind turbine absorbs the kinetic energy from air and transform it to mechanical energy, the SCIG generate the electrical power to fed the electric loads.

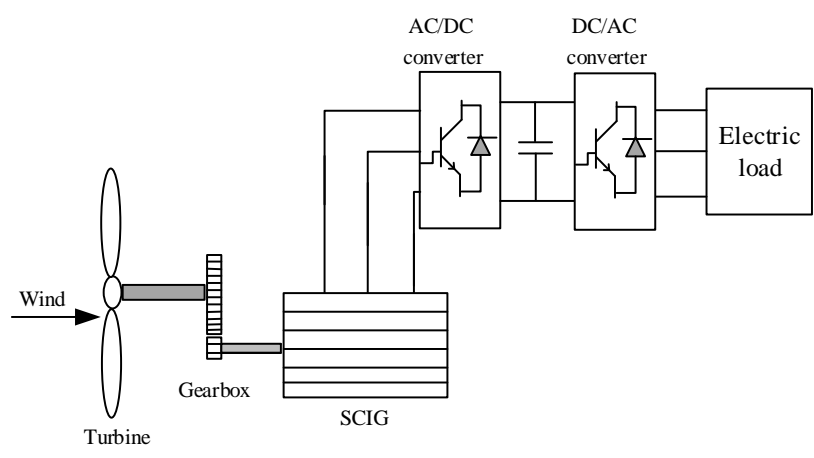

Figure 1. Wind energy conversion system based SCIG

\subsection{Wind turbine modeling}

In the literature a various models of wind turbine have been used, the following model is mostly used (Duong et al, 2014), (Benchagra et al, 2011), (Karabacak, 2019). The power available in air is (Duong et al, 2014):

$$
P_{W T}=\frac{1}{2} \rho \pi R^{2} V^{3}
$$

The mechanical power of wind turbine can be captured from wind is given by:

$$
P_{W T}=\frac{1}{2} C_{P}(\delta, \beta) \rho \pi R^{2} V^{3}
$$

This paper considers the equation of power coefficient $C_{P}$ based on the wind turbine modeled in (Karabacak, 2019)

$$
\begin{gathered}
C_{P}=5.5109\left(\frac{116}{\delta_{i}}-0.4 \beta-5\right) \exp \left(\frac{-21}{\delta_{i}}\right) \\
+0.0068 \delta \\
\delta_{i}=\frac{1}{\delta+0.08 \beta}-\frac{0.035}{\beta^{3}+1}
\end{gathered}
$$

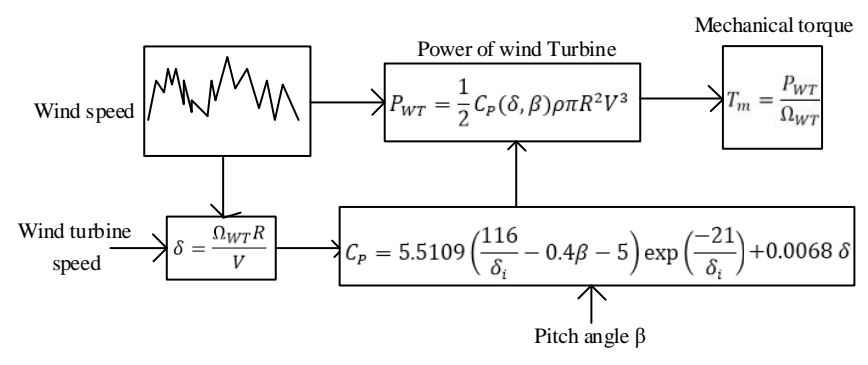

Figure 2. Wind turbine model.

Pitch angle $\beta$ is considered variable in this study.

Fig. 3 shows the relation between power coefficient $C_{p}$ and tip speed ratio $\delta$ for different values of pitch angle $\beta$.

In this study the rated wind speed is $\mathrm{V}_{\mathrm{op}}=12 \mathrm{~m} / \mathrm{s}$

According to Fig. 3 the optimal tip speed ratio $\boldsymbol{\delta}_{\text {opt }}=\mathbf{8 . 1}$ and the maximum power coefficient $\mathrm{C}_{\mathbf{P m a x}}=\mathbf{0 . 4 9}$ are obtained for $\beta=0^{\circ}$.

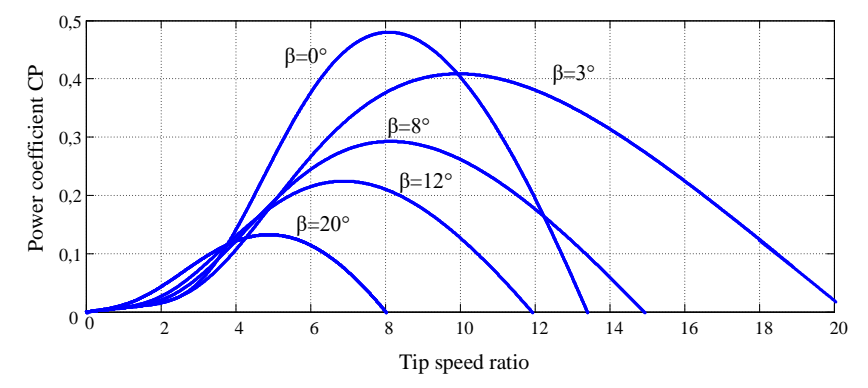

Figure 3. Relation between $C_{p}$ and $\delta$ for different values of $\beta$ 


\subsection{SCIG modeling}

In this paper a modeling of SCIG with coupled magnetic electric circuit theory that allows to highlight the variations of stator and rotor currents caused by broken rotor fault and considering each bar current as independent variable. Different research works detailed this theory (Toliyat et al, 1996), (Munoz et al, 1999) and the model described in (Toliyat et al, 1996) is used in this work.

We consider the following assumptions:

1) The saturation resulted from the magnetization of iron in SCIG is not considered,

2) eddy current, friction, and winding losses are not considered in order to simplify the mathematical model of SCIG by eliminating power losses caused by eddy current in magnetic circuit, mechanical friction and copper losses in stator windings, 3) insulated rotor bars are not considered in order to eliminate stray current between rotor aluminum bars and iron lamination sheets of rotor so no rotor current leakage.

the stator contains symmetric three phases windings and the rotor contain 28 identically bars.

\subsubsection{Stator voltage equations}

$$
\begin{gathered}
{\left[V_{s}\right]=\left[R_{s}\right]\left[I_{s}\right]+\frac{d\left[\emptyset_{s}\right]}{d t}} \\
{\left[\emptyset_{s}\right]=\left[L_{s s}\right]\left[I_{s}\right]+\left[L_{S r}\right]\left[I_{r}\right]}
\end{gathered}
$$

Where

$\left[V_{s}\right]=\left[\begin{array}{lll}V_{s a} & V_{s b} & V_{s c}\end{array}\right]$ Stator voltages

$\left[\mathrm{I}_{s}\right]=\left[\begin{array}{lll}I_{s a} & I_{s b} & I_{s c}\end{array}\right]$ Stator currents

$\left[\emptyset_{s}\right]=\left[\begin{array}{lll}\emptyset_{s a} & \emptyset_{s b} & \emptyset_{s c}\end{array}\right]$ Stator flux

$\left[\mathrm{I}_{r}\right]=\left[\begin{array}{lllll}I_{r 1} & I_{r 2} & \cdots & I_{r 28} & I_{r e}\end{array}\right]$ rotor currents

$\mathrm{I}_{\mathrm{r} 1}, \mathrm{I}_{\mathrm{r} 2}, \mathrm{I}_{\mathrm{r} 3} \ldots \mathrm{I}_{\mathrm{r} 28}$ Rotor bars currents and $\mathrm{I}_{\mathrm{re}}$ rotor end ring segment current

$\left[R_{S}\right]=\left[\begin{array}{ccc}R_{S} & 0 & 0 \\ 0 & R_{S} & 0 \\ 0 & 0 & R_{S}\end{array}\right]$ diagonal $3 \mathrm{X} 3$ matrix of Stator

resistance.

$\left[\mathrm{L}_{s s}\right]=\left[\begin{array}{ccc}L_{s} & L_{s 1 s 2} & L_{s 1 s 3} \\ L_{s 2 s 1} & L_{s} & L_{s 2 s 3} \\ L_{s 3 s 1} & L_{s 3 s 2} & L_{s}\end{array}\right] 3 \mathrm{X} 3$ matrix with $\mathrm{L}_{\mathrm{s}}$ proper stator inductance, and $\mathrm{L}_{\text {sisj }}$ mutual inductance between stator windings with $L_{s i s i}=\frac{L_{S}}{2}$.

$\left[\mathrm{L}_{s r}\right]=\left[\begin{array}{lllll}L_{s 1 r 1} & L_{s 1 r 2} & \ldots & L_{s 1 r 28} & L_{s 1 r e} \\ L_{s 2 r 1} & L_{s 2 r 2} & \ldots & L_{s 2 r 28} & L_{s 2 r e} \\ L_{s 3 r 1} & L_{s 3 r 2} & \ldots & L_{s 3 r 28} & L_{s 3 r e}\end{array}\right] \quad 3 X 29$ matrix with $\mathrm{L}_{\text {sirj }}$ mutual inductance between stator winding and rotor bars.

\subsubsection{Rotor voltage equations}

$$
\begin{gathered}
{\left[V_{r}\right]=\left[R_{r}\right]\left[I_{r}\right]+\frac{d\left[\emptyset_{r}\right]}{d t}} \\
{\left[\emptyset_{r}\right]=\left[L_{r s}\right]\left[I_{s}\right]+\left[L_{r r}\right]\left[I_{r}\right]}
\end{gathered}
$$

Where

$\left[V_{r}\right]=\left[\begin{array}{llll}0 & 0 & \ldots & 0\end{array}\right] 29$ column of rotor voltages

$\left[\emptyset_{r}\right]=\left[\begin{array}{lllll}\emptyset_{r 1} & \emptyset_{r 2} & \ldots & \emptyset_{r 28} & \emptyset_{r e}\end{array}\right] 29$ column of rotor flux

$\left[\mathrm{I}_{r}\right]=\left[\begin{array}{lllll}I_{r 1} & I_{r 2} & \cdots & I_{r 28} & I_{r e}\end{array}\right] 29$ column of rotor currents

$\left[R_{\mathrm{r}}\right]$

$=\left[\begin{array}{cccccc}2\left(R_{b}+R_{e}\right) & -R_{b} & 0 & \cdots & -R_{b} & -R_{e} \\ -R_{b} & 2\left(R_{b}+R_{e}\right) & -R_{b} & \cdots & 0 & -R_{e} \\ \vdots & \vdots & \vdots & \ddots & \vdots & \vdots \\ 0 & 0 & 0 & \cdots & -R_{b} & -R_{e} \\ -R_{b} & 0 & 0 & \cdots & 2\left(R_{b}+R_{e}\right) & -R_{e} \\ -R_{e} & -R_{e} & -R_{e} & \cdots & -R_{e} & 28 R_{e}\end{array}\right]$

29X29 Matrix of rotor resistance, with $\mathrm{R}_{\mathrm{b}}$ resistance of one rotor bar, $\mathrm{R}_{\mathrm{e}}$ resistance of rotor end ring segment.

$\left[\mathrm{L}_{r s}\right]=\left[\mathrm{L}_{s r}\right]^{T}$

$\left[L_{\mathrm{r}}\right]=$

$\left[\begin{array}{ccccc}L_{r} & L_{r 1 r 2}-L_{b} & \cdots & L_{r 1 r 28}-L_{b} & -L_{e} \\ L_{r 2 r 1}-L_{b} & L_{r} & \cdots & 0 & -L_{e} \\ \vdots & \vdots & \ddots & \vdots & \vdots \\ L_{r 28 r 1}-L_{b} & L_{r 28 r 2} & \cdots & L_{r} & -L_{e} \\ -L_{e} & -L_{e} & \cdots & -L_{e} & 28 L_{e}\end{array}\right]$

29X29 Matrix of rotor inductance with $L_{r}=L_{m r}+2\left(L_{b}+\right.$ $L_{e}$ ), $\mathrm{L}_{m r}$ is the magnetizing inductance of rotor bars, $\mathrm{L}_{\mathrm{b}}$ is the leakage inductance of rotor bar, $L_{e}$ is the leakage inductance of rotor end ring segment.

\subsection{3 mechanical equations}

$$
T_{e}=\left[\frac{d W_{c o}}{d \theta_{r}}\right]
$$

Where

Te: electromagnetic torque, $\mathrm{W}_{\mathrm{co}}$ : is the magnetic coenergy and $\theta_{\mathrm{r}}$ : rotation angle.

As detailed in (Toliyat et al, 1996) the electromagnetic torque is defined as following:

$$
T_{e}=\frac{1}{2}\left[\left[I_{s}\right]^{T}\left[\frac{d L_{s r}}{d \theta_{r}}\right]\left[I_{r}\right]\right]
$$

\section{PROPOSED APPROACH}

The figure 4 shows four zones of wind turbine operating, zone- 1 is the start-up of the wind turbine, zone-2 is the optimization of power with MPPT control, zone-3 is the constant power production, zone-4 no power production. 


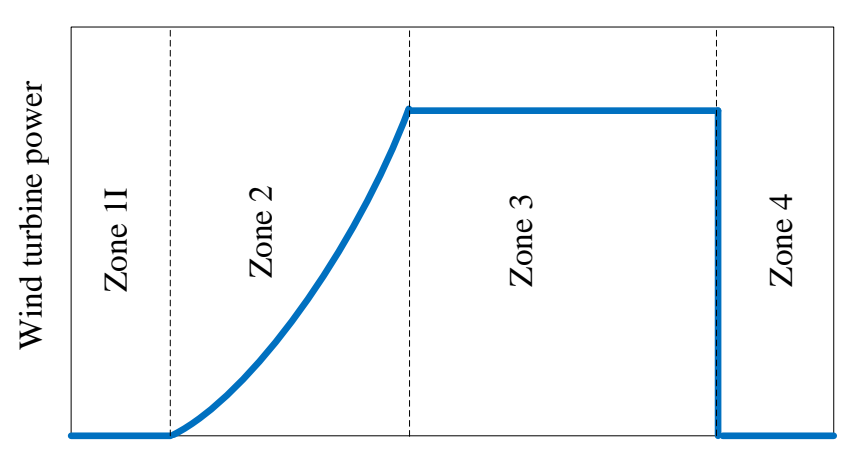

Wind speed

Figure 4. zones of wind turbine operating

In this paper we focus our study in zone-3, the figure 5 represent the global scheme of our approach.

This approach is developed in order to achieve condition monitoring and drift-like fault detection of rotor bars failure in SCIG based WECS by detecting the drift SCIG operating conditions from normal (healthy rotor bars) to faulty operation (broken of several rotor bars).

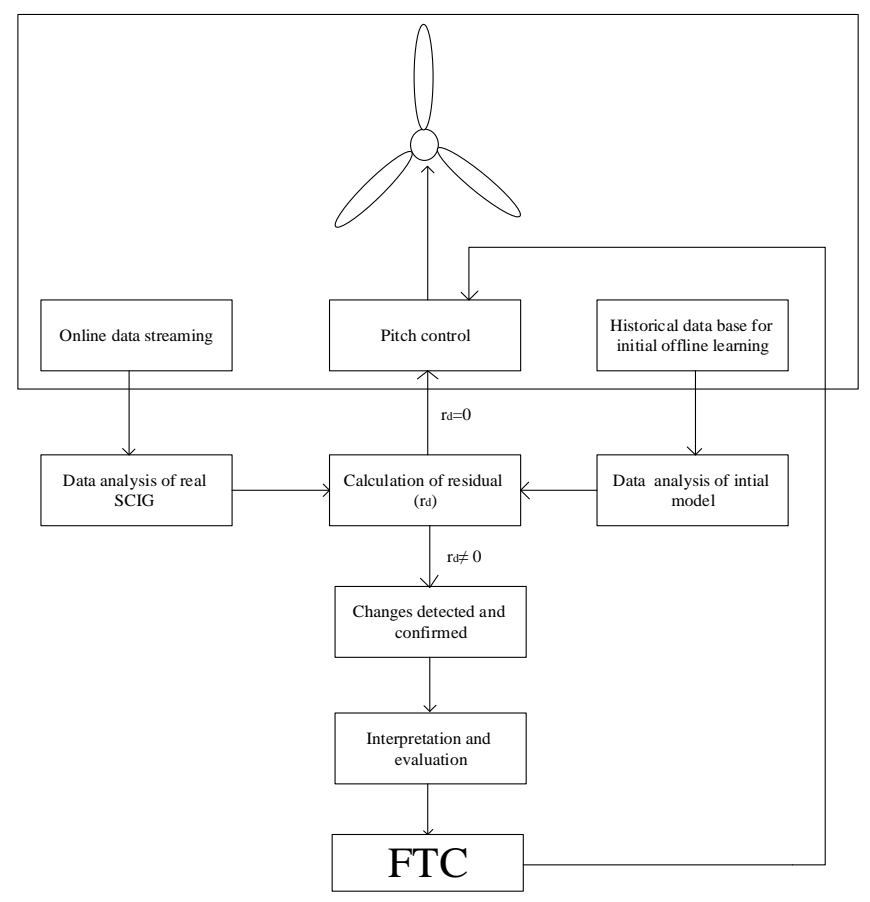

Figure 5. Proposed approach scheme

The proposed approach is developed on 6 steps as following:

\subsection{Online data streaming:}

Measurement online with sensors of wind speed (V), pitch angle $(\beta)$, stator currents $\left(I_{s}\right)$ and estimate the rotor currents $\left(\mathrm{I}_{\mathrm{r}}\right)$.

\subsection{Historical data base for initial offline learning}

In this stage, a real SCIG is used to extract the historical initial data base in healthy mode, one bar failure mode and two bars failure mode. The data is measurements about stator currents $\left(I_{S}\right)$, rotor currents $\left(I_{r}\right)$ and harmonic analyzation of stator current.

\subsection{Data analysis:}

This step aims at findings the residuals that are sensitive to the system in healthy or faulty operating conditions to construct the required diagnosis system, these residuals will be responsible of detection and isolation of broken bars in SCIG rotor based on signals provided by harmonic analyzer of stator currents as well as the prior knowledge about the system dynamics. The harmonic analyzer is based on FFT method to detect the harmonics in stator currents caused by broken rotor bars.

\subsection{Calculation of residual $\left(r_{d}\right)$, Changes detected and confirmed, Interpretation and evaluation.}

The residuals are generated by a comparison between the data analysis of initial healthy model and the data analysis of real SCIG. If the real SCIG corresponds to healthy initial model, the residual is equal to zero $\left(r_{d}=0\right)$ and the pitch control remains the same without FTC. When the residual $r_{d} \neq 0$, the changes are detected and confirmed, the interpretation and evaluation are as followings:

- If the real SCIG corresponds to faulty model with one broken rotor bar, the residual is equal to 1 .

- If the real SCIG corresponds to faulty model with two broken rotor bars, the residual is equal to 2 .

\subsection{Fault tolerant control (FTC)}

The healthy SCIG contains 28 bars, with nominal rotor current $I_{r n}$, and rated power $P_{n}$. If one rotor bar is broken, the new rotor current in healthy bars:

$$
I_{r f 1}=\frac{28}{27} I_{r n}
$$

If two rotor bars are broken, the new rotor current in healthy bars:

$$
I_{r f 2}=\frac{28}{26} I_{r n}
$$

To make a nominal rotor current in faulty conditions, the proposed FTC calculate the new rated power $\left(\mathrm{P}_{\mathrm{nf}}\right)$

$$
\begin{aligned}
& P_{n f 1}=\frac{27}{28} P_{n} \\
& P_{n f 2}=\frac{26}{28} P_{n}
\end{aligned}
$$

So if the residual $r_{d}=0$, the rated power of SCIG is $P_{n}$. 
If $r_{d}=1$, the rated power of SCIG is $P_{n f 1}$.

If $r_{d}=2$, the rated power of SCIG is $P_{n f 2}$

\subsection{Pitch control}

The pitch control step is summarized in following scheme:

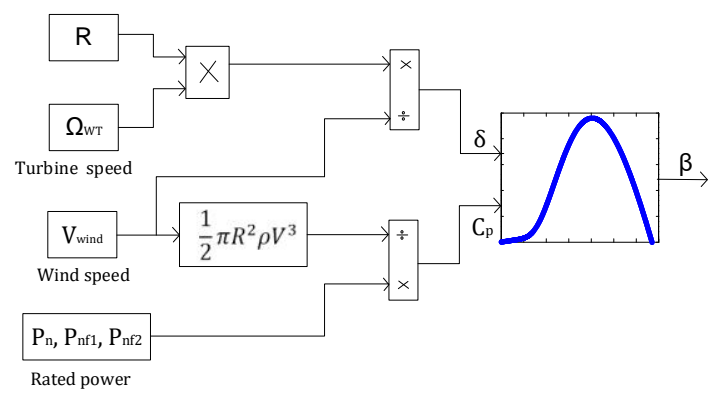

Figure 6. Pitch control

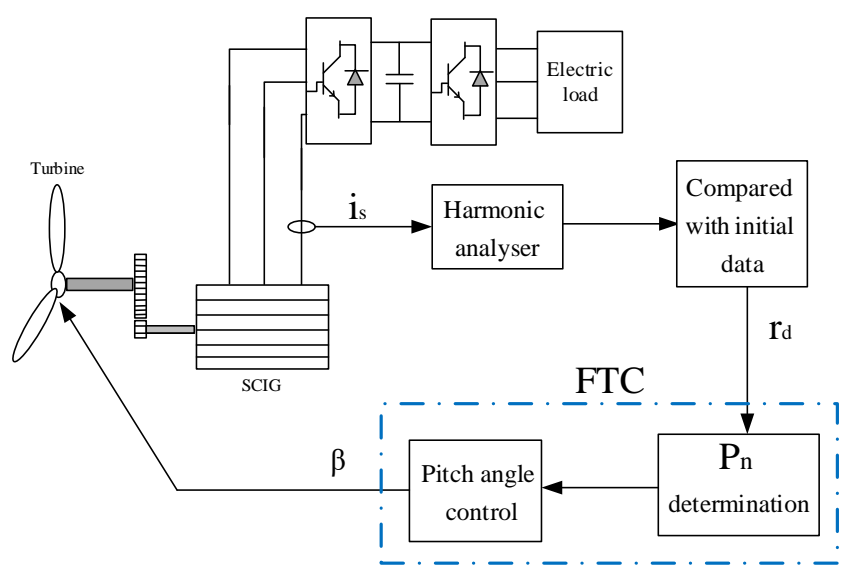

Figure 7. proposed FTC for SCIG based wind turbine

In the figure 7, a global scheme of proposed FTC applied in SCIG based wind turbine under rotor bars failure.

\section{Simulation RESUlTS}

The proposed approach is validated using MATLAB software and the simulation parameters are summarized in table 1.

Table 1. simulation parameters

\begin{tabular}{|c|c|}
\hline $\mathrm{P}_{\mathrm{n}}$ & 3500 watt \\
\hline $\mathrm{V}_{\mathrm{s}}$ & $220 \mathrm{~V}$ \\
\hline $\mathrm{R}_{\mathrm{s}}$ & $3.35 \Omega$ \\
\hline $\mathrm{L}_{\mathrm{s}}$ & $0.028 \mathrm{H}$ \\
\hline $\mathrm{R}_{\mathrm{e}}$ & $1.6 \mathrm{e}-6 \Omega$ \\
\hline $\mathrm{R}_{\mathrm{b}}$ & $68.34 \mathrm{e}-6 \Omega$ \\
\hline $\mathrm{L}_{\mathrm{b}}$ & $0.28 \mathrm{e}-6 \mathrm{H}$ \\
\hline $\mathrm{L}_{\mathrm{e}}$ & $0.3 \mathrm{e}-6 \mathrm{H}$ \\
\hline
\end{tabular}

\subsection{Simulation of historical data base for initial offline learning.}

As mentioned in section 3 the historical initial data base is to extract the following data from real SCIG:

- Harmonic analyzation as shown in figures 8, 9 and 10) in both health and faulty modes of SCIG using FFT method,

- The stator currents as shown in figure 11,

- $\quad$ The rotor currents as shown in figure 12.

The FFT spectrum analysis of stator current in SCIG with one broken bar is depicted in figure 9. This figure shows two spectrums with $3 \%$ of fundamental magnitude and frequencies of 47 and $53 \mathrm{~Hz}(\mathrm{f} \pm 3 \mathrm{~Hz})$.

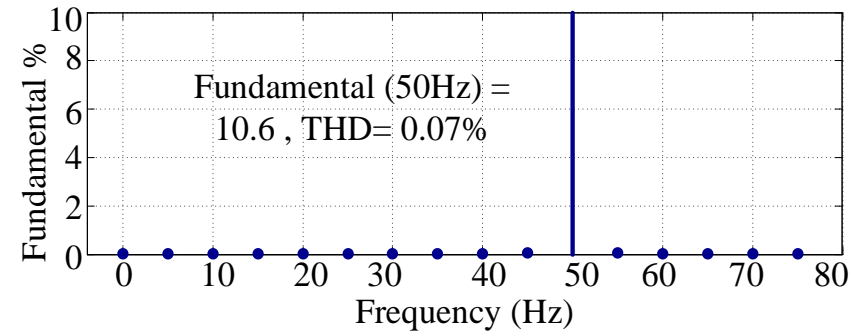

Figure 8. stator current spectrum in healthy SCIG.

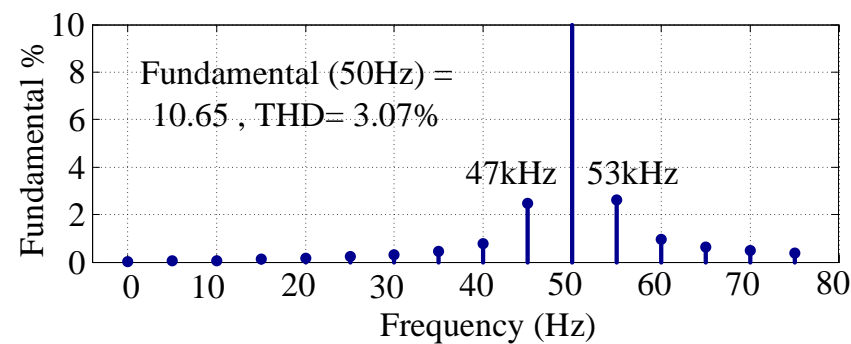

Figure 9. stator current spectrum in SCIG with one broken rotor bar.

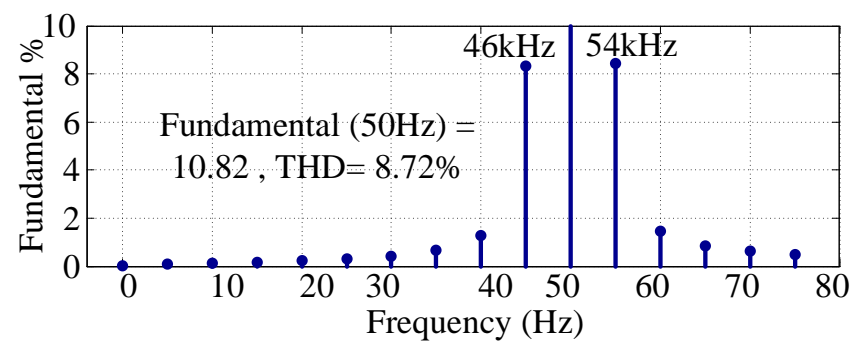

Figure 10. stator current spectrum in SCIG with two broken rotor bars.

In figure 10 , the spectrums with $8.7 \%$ of fundamental magnitude shows a two broken bars in SCIG.

The figure 11 and figure 12 shows the stator and rotor currents respectively in healthy SCIG 


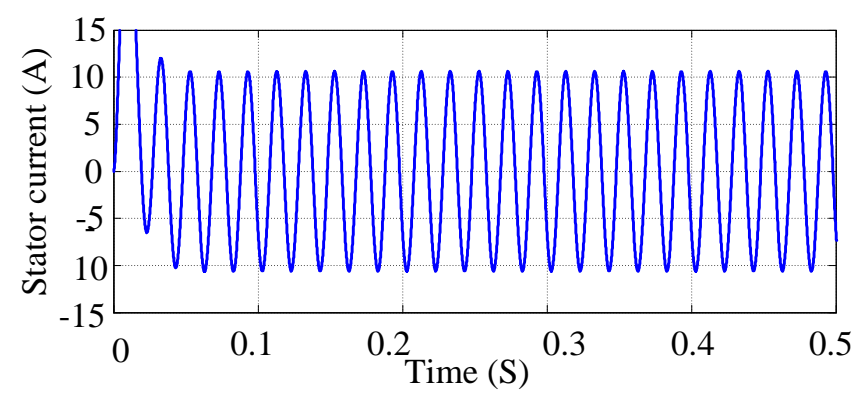

Figure 11. stator current in healthy SCIG.

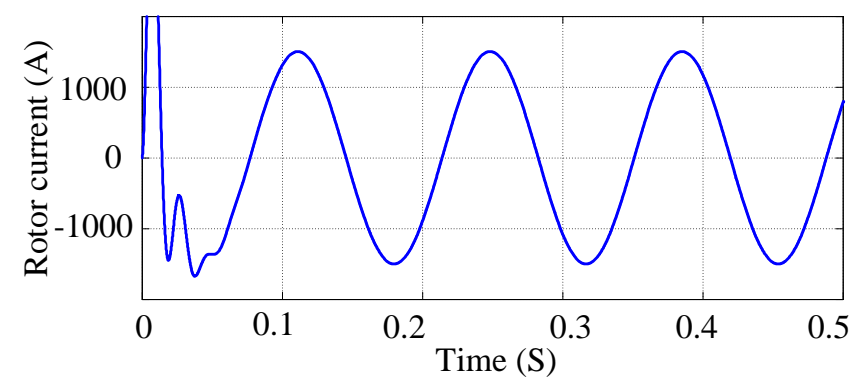

Figure 12. rotor current in healthy SCIG.

\subsection{Simulation without FTC}

In this section, a healthy SCIG between $5 \mathrm{~S}$ and $12 \mathrm{~S}$, one broken bar between $12 \mathrm{~S}$ and $21 \mathrm{~S}$, two broken bars between $21 \mathrm{~S}$ and $30 \mathrm{~S}$
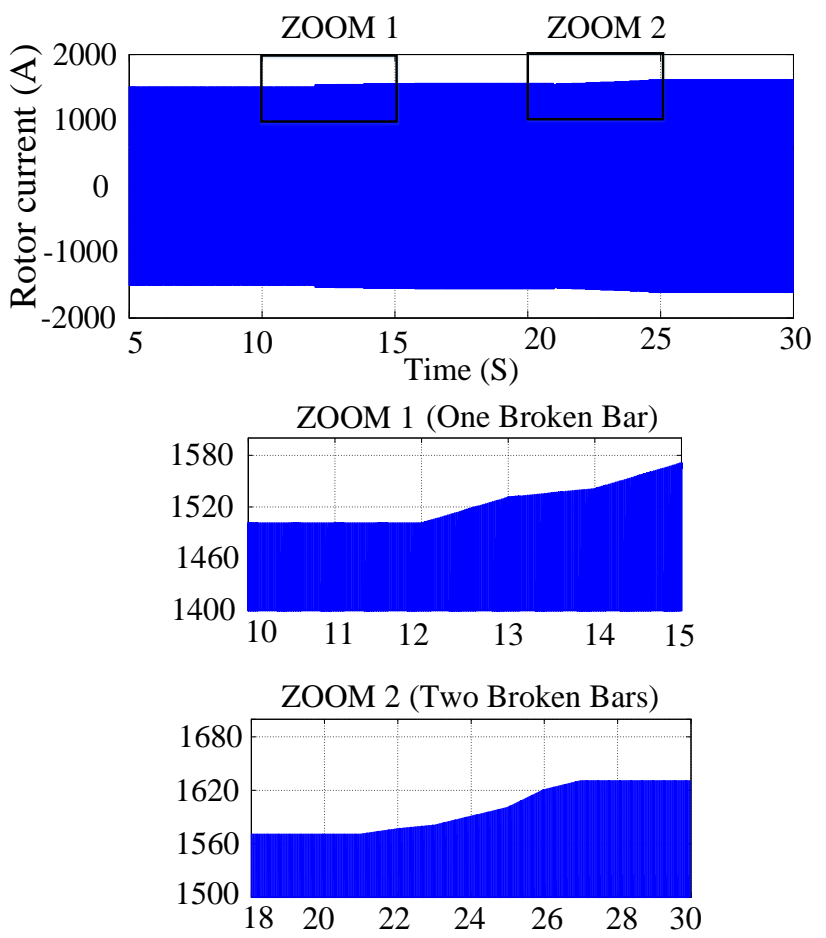

Figure 13. rotor current of SCIG without FTC.

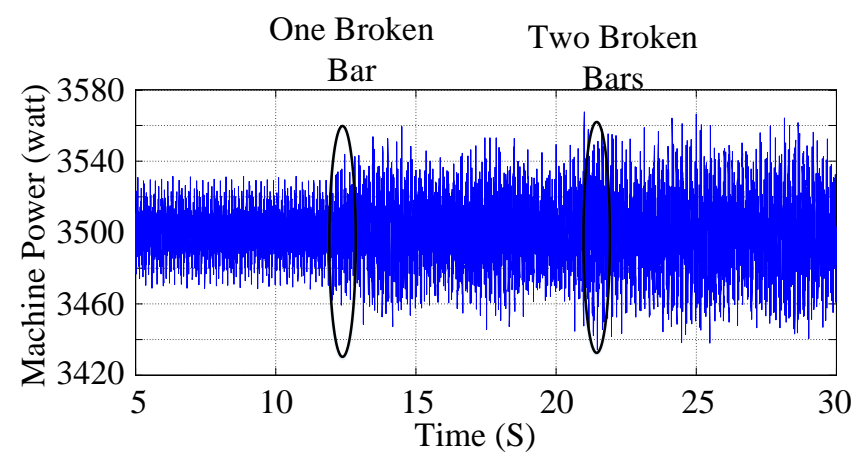

Figure 14. power of SCIG without FTC.

Figure 13 shows the rotor current with $1500 \mathrm{~A}$ of $\max$ magnitude in healthy mode, at $12 \mathrm{~S}$ one bar is broken which increase the rotor current by $70 \mathrm{~A}$, at $21 \mathrm{~S}$ two bars are broken which increase the rotor current by $130 \mathrm{~A}$. So the healthy rotor bars are overloaded and these can cause their breaking or shutdown of SCIG.

The figure 14 shows the power of SCIG which equal to 3500watt

\subsection{Simulation with FTC}
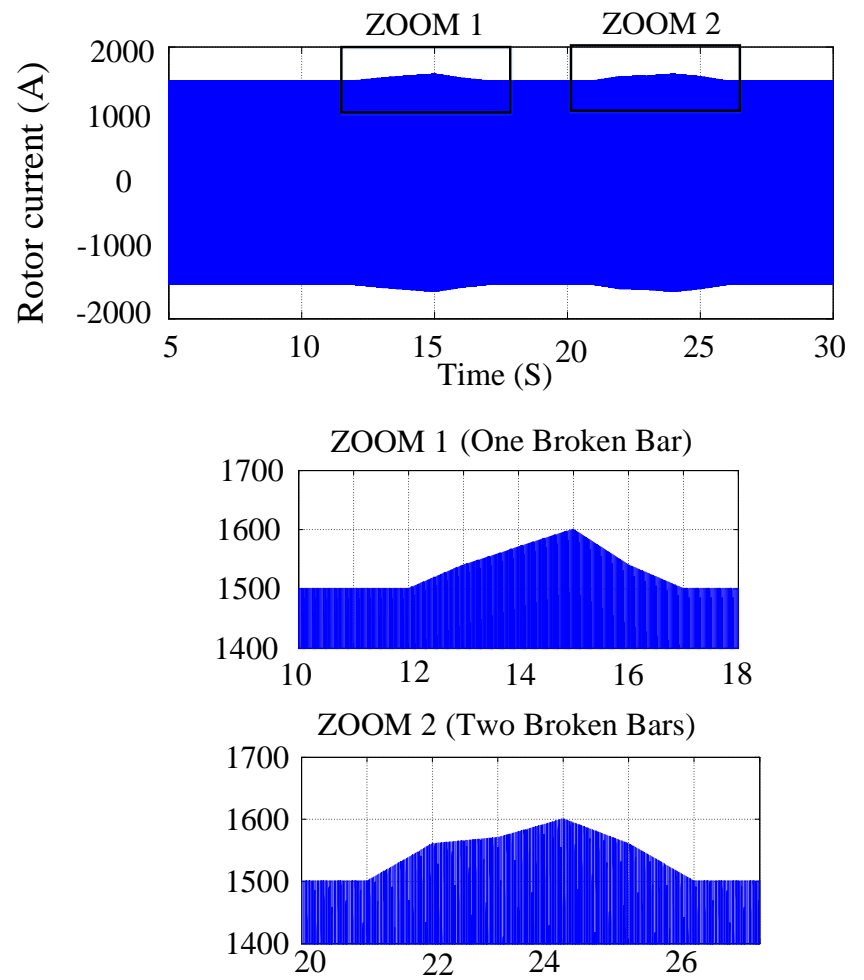

Figure 15. rotor current of SCIG with FTC 


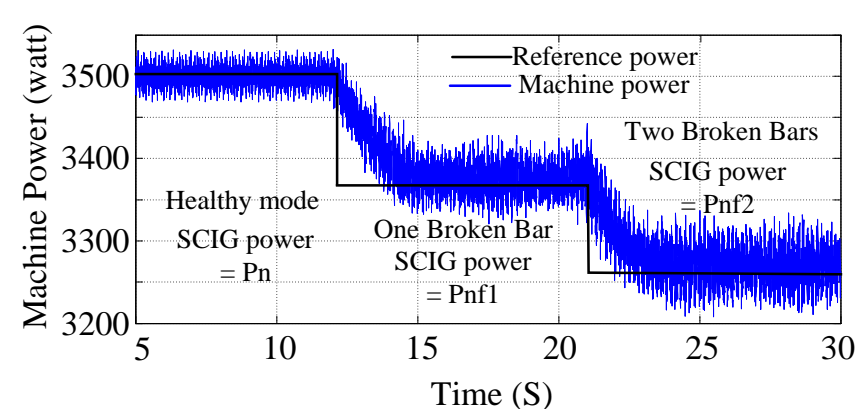

Figure 16. power of SCIG with FTC.

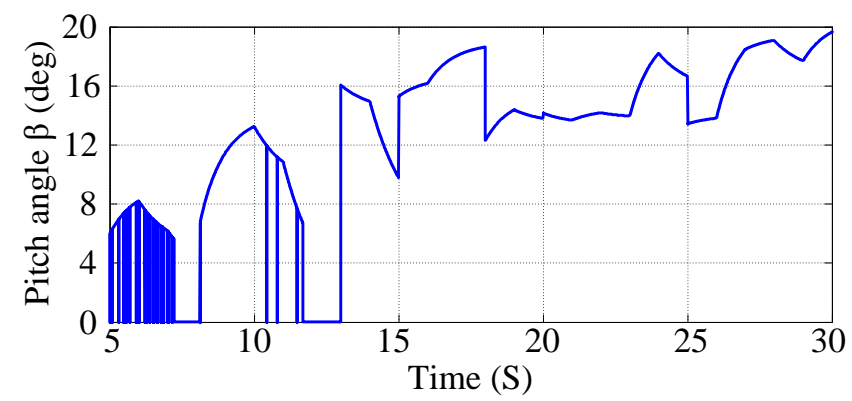

Figure 17. pitch angle $\beta$ with FTC.

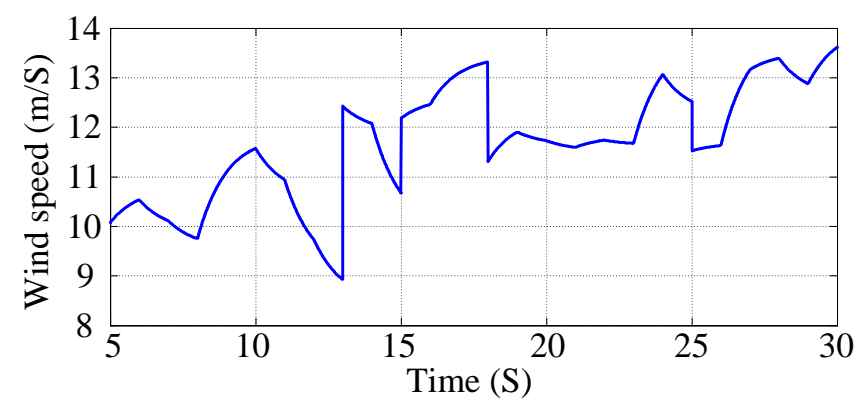

Figure 18. wind speed.

In this section a fault tolerant control (FTC) to minimize the current of rotor bars when one or two bars are broken.

In figure 15, the rotor current is equal to nominal current (max magnitude 1500A) when one bar is broken after transient state of $6 \mathrm{~S}$. When two bars are broken, the rotor current is equal to nominal current (max magnitude 1500A) after $5 \mathrm{~S}$ of transient state.

Figure 16 shows the power of SCIG and their reference in both healthy and faulty modes. When one or two bars are broken, the power of SCIG is decreased to maintain the rotor currents at their nominal value. This power is adjusted using the pitch angle control. As shown in figure 17, the pitch angle is varied according to wind speed (Figure 18) and the power calculated by FTC. This change in pitch angle allows avoiding the overload of SCIG during rotor bar failures and therefore avoiding the excessive heating in stator windings and mechanical stress in rotor. Consequently, the lifetime of SCIG and its sustainability are improved.

\section{CONCLUSION}

In this paper a fault diagnosis and fault tolerant control (FTC) of SCIG based wind turbine in optimal power zone ( $3^{\text {rd }}$ zone) when one or two rotor bars are broken. Simulations with MATLAB shows the effectiveness of proposed method to decrease the rotor bar current to a nominal value when a fault has been occurring in these bars by minimizing the nominal power of SCIG which can prevents the propagation of faults to healthy bars and generate a pitch control method to guarantee a nominal power even when the wind speed is increased. These results confirm that the sustainability of wind system based SCIG is improved by increasing the lifetime of SCIG with nominal rotor current under faulty mode and the shutdown is avoided. As further directions we propose to deal with fault tolerant control of WECS using active power filters.

\section{NOMENCLATURE}

$P_{W T} \quad$ Wind turbine power.

$\rho \quad$ Air density.

$R \quad$ Rayon of wind turbine.

$V \quad$ Wind speed.

$\mathrm{C}_{\mathrm{P}} \quad$ Power coefficient.

$\beta \quad$ Pitch angle.

$\delta \quad$ Tip speed ratio.

$V_{s}, V_{r} \quad$ Stator and rotor voltages.

$I_{s}, I_{r} \quad$ Stator and rotor currents.

$\phi_{s}, \phi_{r} \quad$ Stator and rotor flux.

$\mathrm{Te} \quad$ electromagnetic torque.

$P_{n} \quad$ nominal power of SCIG

\section{REFERENCES}

Benchagra, M., Hilal, M., Errami, Y., Ouassaid, M., \& Maaroufi M. (2011). Modeling and control of SCIG based variable-speed with power factor control. International Review of Modelling and Simulations, vol. 4(3), pp. 1007-1014.

Chen, Z. (2013). Wind power in modern power systems. $J$ Mod Power Syst Clean Energy, vol. 1(1), pp. 2-13. doi:10.1007/s40565-013-0012-4.

Duong, M. Q., Grimaccia, F., Leva, S., Mussetta, M., \& Ogliari, E. (2014). Pitch angle control using hybrid controller for all operating regions of SCIG wind turbine system. Renewable Energy, vol. 70, pp. 197-203. doi:10.1016/j.renene.2014.03.072.

Fernando, D. B., Hernan, D. B., \& Ricardo, J. M. (2007). Wind Turbine Control Systems. Germany: SpringerVerlag London Limited.

Karabacak, M. (2019). A new perturb and observe based higher order sliding mode MPPT control of wind turbines eliminating the rotor inertial effect. Renewable Energy, vol. 133, pp. 807-827. doi:10.1016/j.renene.2018.10.079. 
Lahcène, N., Hafaifa, A., Kouzou, A., Guemana, M., \& Abudura, S. (2016). Detecting rotor faults of SCIG based wind turbine using PSD estimation methods. 8th International Conference on Modelling, Identification and Control (566-572), November 15-17, Algeria. doi:10.1109/ICMIC.2016.7804176.

Lešić, V., Vašak, M., Perić N., Wolbank, T. M., \& Joksimović, G. (2013). Fault-tolerant control of a wind turbine with a squirrel-cage induction generator and rotor bar defects. Automatika Journal for Control, Measurement, Electronics, Computing and Communications, vol. 54(3), pp. 316-328. doi:10.7305/automatika.54-3.189.

Luo, N., Vidal, Y., \& Acho, L. (2014). Wind turbine control and monitoring. Switzerland: Springer International Publishing

Md Emrad, H. (2017). A non-linear controller based new bridge type fault current limiter for transient stability enhancement of DFIG based Wind Farm. Electric Power Systems Research, vol. 152, pp. 466-484. doi:10.1016/j.epsr.2017.07.033.

Md Emrad, H. (2017). Application of gaussian mixture regression model for short-term wind speed forecasting. Proceeding in IEEE North American Power Symposium (1-6), Sept 17-19, Morgantown, WV, USA. doi: 10.1109/NAPS.2017.8107222.

Md Emrad, H. (2018). Low Voltage Ride-Through Capability Improvement Methods for DFIG based Wind Farm. Journal of Electrical Systems and Information Technology, vol. 5(3), pp. 550-561. doi:10.1016/j.jesit.2017.12.002.

Munoz, A.R., \& Lipo, T.A. (1999). Complex vector model of the squirrel-cage induction machine including instantaneous rotor bar currents. IEEE Transactions on Industry Applications, vol. 35(6), pp. 1332 - 1340. doi:10.1109/28.806047.

Obaid M. M., Varagnolo, D., Nikolakopoulos, G., \& Gustafsson, T. (2016). Detecting broken rotor bars in induction motors with model-based support vector classifiers. Control Engineering Practice, vol. 52, pp. 15-23. doi:10.1016/j.conengprac.2016.03.019;

Park, Y. S., Jang, S. M., Choi, J. Y., \& Goo, C. S. (2012). Fault detection of squirrel cage induction motor by analyzing motor current signals. IEEE Vehicle Power and Propulsion Conference (219-222), Oct 9-12, Seoul, Korea. doi:10.1109/VPPC.2012.6422532.

Rahimi, M., \& Asadi, M. (2019). Control and dynamic response analysis of full converter wind turbines with squirrel cage induction generators considering pitch control and drive train dynamics. Electrical Power and Energy Systems, vol. 108, pp. 280-292. doi:10.1016/j.ijepes.2019.01.018.

Seyoum, D., Grantham, C., \& Fazlur Rahman, M. (2003). The dynamic characteristics of an isolated self-excited induction generator driven by a wind turbine. IEEE
Transactions On Industry Applications, vol. 39(4), pp. 936-944. doi:10.1109/TIA.2003.813738.

Toliyat, H. A., Arefeen, M. S., \& Parlos, A. G. (1996). A method for dynamic simulation of air-gap eccentricity in induction machines. IEEE transactions on industry applications, vol. 32(4), pp. 910-918. doi: 10.1109/28.511649.

Toliyat, H. A., Nandi, S., Choi, S., \& Meshgin-kelk, H. (2013). Electric machines: Modeling, condition monitoring, and fault diagnosis. Boca Raton: CRC Press Taylor \& Francis Group. 